\title{
A parametric study on the axial behaviour of elastomeric isolators in multi-span bridges subjected to horizontal seismic excitations
}

\author{
E. Tubaldi ${ }^{1}$ S. A. Mitoulis ${ }^{2}$ H. Ahmadi ${ }^{3} \cdot$ A. Muhr $^{3}$
}

Received: 1 October 2015/Accepted: 28 January 2016/Published online: 19 February 2016

(C) The Author(s) 2016. This article is published with open access at Springerlink.com

\begin{abstract}
This paper investigates the potential tensile loads and buckling effects on rubber-steel laminated bearings on bridges. These isolation bearings are typically used to support the deck on the piers and the abutments and reduce the effects of seismic loads and thermal effects on bridges. When positive means of fixing of the bearings to the deck and substructures are provided using bolts, the isolators are exposed to the possibility of tensile loads that may not meet the code limits. The uplift potential is increased when the bearings are placed eccentrically with respect to the pier axis such as in multi-span simply supported bridge decks. This particular isolator configuration may also result in excessive compressive loads, leading to bearing buckling or in the attainment of other unfavourable limit states for the bearings. In this paper, an extended computer-aided study is conducted on typical isolated bridge systems with multi-span simply-supported deck spans, showing that elastomeric bearings might undergo tensile stresses or exhibit buckling effects under certain design situations. It is shown that these unfavourable conditions can be avoided with the rational design of the bearing properties and in particular of the shape factor, which is the geometrical parameter controlling the axial bearing stiffness and capacity for a
\end{abstract}

\section{S. A. Mitoulis \\ s.mitoulis@surrey.ac.uk; \\ http://www.mitoulis.com \\ E. Tubaldi \\ etubaldi@gmail.com}

H. Ahmadi

hahmadi@tarrc.co.uk

\section{A. Muhr}

amuhr@tarrc.co.uk

1 Department of Civil and Environmental Engineering, Imperial College London, London, UK

2 Department of Civil and Environmental Engineering, Faculty of Engineering and Physical Sciences, University of Surrey, Guildford, Surrey GU2 7XH, UK

3 Tun Abdul Razak Research Centre (TARRC), Brickendonbury, Brickendon Lane, Hertford, UK 
given shear stiffness. Alternatively, the unfavourable conditions could be reduced by reducing the flexural stiffness of the continuity slab.

Keywords Bridges - Seismic isolation - Steel-laminated elastomeric bearings - Tensile stress $\cdot$ Buckling $\cdot$ Shape factor

\section{Introduction}

Seismic isolation with rubber-steel laminated bearings is used extensively in contemporary bridge engineering as a means of mitigating the effect of earthquake loads by reducing the forces transmitted to the substructures (Lee et al. 2001; Chen and Duan 2003; Tubaldi and Dall'Asta 2011). Bridge isolation bearings are designed mainly to sustain the compressive loads, transmitted from the deck, while accommodating horizontal and rotational deflections. However, under some design situations they may be exposed to the possibility of uplift and to tensile loads during an earthquake. These loadings may be induced by the seismic motion of the deck along the longitudinal (Mitoulis 2014) and/or the transverse direction of the bridge (Katsaras et al. 2009), when the bearings are fixed to the superstructure and the substructures through bolted connections, as often suggested by seismic codes (EN1337-3 2005; EN15129 2009). The occurrence of tensile forces in isolation bearings has been reported in many reconnaissance surveys such as those following the 2011 Tohoku earthquake (Buckle et al. 2012) and also in experimental shaking-table tests on isolated structures, as discussed in Yang et al. (2010).

Rubber-steel laminated bearings are vulnerable to tensile loads. In fact, it has long been known that hydrostatic tensile stress causes internal local ruptures in the rubber known as cavitation (Gent and Lindley 1959; Gent 1990; Pond 1995; Dorfmann and Burtscher 2000). Void nucleation and the growth of microcavities in rubber is a complex process that involves breakage of bonds in the polymer network, fracture of filler clusters and detachments of rubber chains from reinforcing particles. While in compression the rubber can easily withstand high pressures without exhibiting damage (Gent 1990), the tensile stresses, at which cavitation initiates, are very low. According to Gent and Lindley (1959), cavitation occurs at a negative pressure of about $2.5 \mathrm{G}$, where $G$ is the shear modulus of the bearing, obtained experimentally from testing at moderate shear strain (between 100 and $200 \%$ ) under nominal axial loads (Kumar et al. 2014). The load deformation of the isolators under pure tensile loads has been described by Constantinou et al. (2007) and Warn et al. (2007). Yang et al. (2010) tested bearings that had a shear modulus of $0.55 \mathrm{MPa}$ under pure tensile loads and identified that the bearings exhibit cavitation when the tensile strains exceeded $1.0 \%$ (corresponding to tensile stress between 1 and $2 \mathrm{MPa}$ ). The potential of bearing uplift, i.e. tension, is also evident throughout most bridge design codes (AASHTO 2012; CalTrans 1999; EN1998-2 2005; JRA 2002), providing rules to limit the likelihood of occurrence.

In order to adequately describe the behaviour of laminated rubber-steel isolation bearings in bridges, accurate models are required, which are capable of simulating the response under a combined state of stress following the imposition of shear and vertical loadings. Kumar et al. (2014) recently developed models for describing the combined axial, rotational, and shear response of different types of laminated steel-rubber bearings, including low damping rubber bearings, high-damping rubber bearings, and lead rubber 
bearings. The proposed models have been implemented in OpenSees (McKenna et al. 2006) and can simulate the coupling of vertical and horizontal deflection, cavitation and post-cavitation behaviour in tension and strength degradation in cyclic tensile loading due to cavitation.

This study analyses the potential of occurrence of tensile failure or of other limit states related to bearing performance (EN15129 2009; EC8-2 2005; EN1337-3 2005) in multispan simply supported bridges having steel-rubber laminated bearings placed eccentrically with respect to the vertical axis of the piers. This type of bridge configuration may be particularly vulnerable to bearing failure due to excessive axial loads (Mitoulis 2014). In fact, the longitudinal seismic motion of the deck induces rotations to the pier caps about the transverse axis, which in turn causes either tensile or compressive displacements to the bearings, depending upon the position of the isolators on the pier cap and the direction of loading, as shown in Fig. 1. The longitudinal seismic excitation also induces vertical motion of the deck as well as flexure of the continuity slab. An accurate numerical model is required to describe the aforementioned phenomena, which influence the axial forces in the bearings.

In this paper, the case of high-damping natural rubber (HDNR) bearings is considered and a bridge model representative of typical bridge design practice is analysed first to shed light on the coupled horizontal-vertical bearing behaviour. For this purpose, the model developed for Kumar et al. (2014) is employed to accurately simulate the HDNR bearing response and the results of tests carried out at TARRC on HDNR double-shear specimens are used to calibrate the bearing model parameters.

An extensive parametric study is then carried out to identify under which design situations the uplift effect is critical, i.e. for which properties of the superstructure, the substructures, the bearings, and the pier-to-deck connection (i.e. the eccentricity of the bearings with regards the axis of the pier), the uplift effect is more likely to occur. It is noteworthy though that the self-weight and the additional variable loads of the deck induce compression on the bearings, which protect them against cavitation. However, the same loads increase the vulnerability of the isolators to buckling and to other limit states as described by EN15129 (2009), EC8-2 (2005), and of EN1337-3 (2005). For this reason, the bearings are checked against all these limit state conditions, thus ensuring their reliable behaviour under both the seismic and non-seismic loading conditions. Furthermore, emphasis is placed on the effect of the shape factor, which controls the vertical behaviour and stiffness of the bearing for a given horizontal stiffness. The results of the parametric
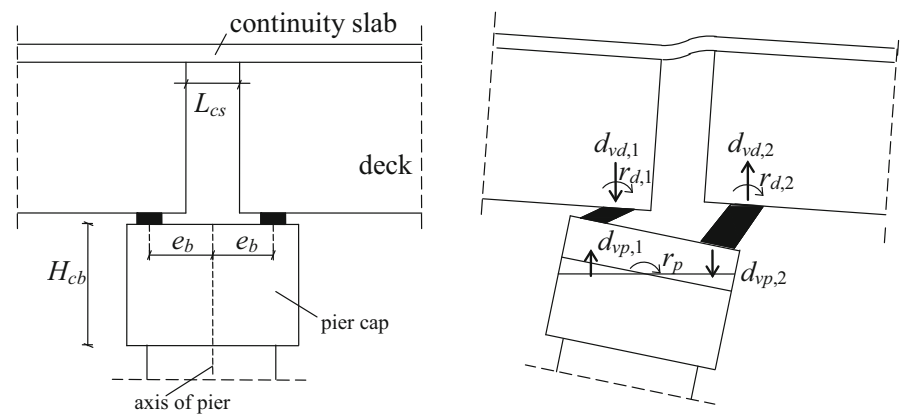

Fig. 1 a Geometry of the pier cap, b different contributions to the axial bearing deflections 
study provide useful information on the sensitivity of the uplift mechanism to the properties of the bridge and the bearing and sheds light on the most critical limit states of eccentrically-placed bearings.

\section{Bridge modelling and seismic input}

\subsection{Description of the reference bridge}

A typical isolated bridge configuration is considered in this study, as shown in Fig. 2. This bridge configuration is representative of many bridges in Europe with simply-supported pre-cast and pre-stressed concrete I-beams seated on HDNR bearings.

The deck comprises three simply-supported spans of length $L_{s p}=30 \mathrm{~m}$, each consisting of five precast I-beams and by a cast-in situ slab, whose width is $13.45 \mathrm{~m}$, whereas the carriageway width is considered to be $11.5 \mathrm{~m}$. The deck spans are connected by castin situ continuity slabs reinforced with ordinary reinforcement. This connection of the adjacent spans provides a continuous deck surface, thus avoiding the use of expansion joints at the piers. Despite the connection of the adjacent segments, the bridge behaves, under the vertical loads, as if it consisted of a series of simply-supported beams, provided that the slab is sufficiently flexible to accommodate the rotations. The class of the concrete employed for the deck is C30/40 whereas the class of steel is S355 for the ordinary reinforcement and S1570/1770 for the prestressed.

The deck I-beams sit on the piers through two lines of five steel-laminated isolation bearings, as shown in Fig. $2 b$ and on one line of five bearings on the abutments, i.e. a total of ten bearings are used on the piers and five bearings on each abutment. The eccentricity of the axis of the isolators with respect to the axis of the pier is $e_{b}=0.8 \mathrm{~m}$. The deck has a depth of $2.02 \mathrm{~m}$ and comprises the precast beams of depth equal to $1.75 \mathrm{~m}$ and a slab $0.27 \mathrm{~m}$ thick. The eccentricity of the neutral axis of the deck with respect to the bottom fibre of the deck is $H_{d g}=1.47 \mathrm{~m}$. The slab is continuous along the total length of the bridge, whilst two expansion joints are used at the abutments. The eccentricity of the continuity slab with respect to the deck neutral axis is $e_{c s}=0.4 \mathrm{~m}$.

(a)

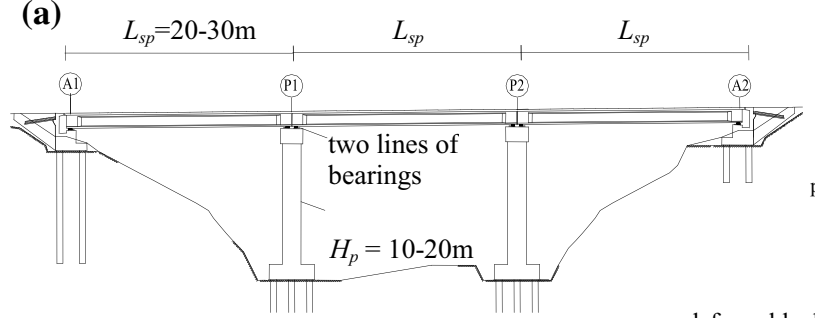

$D_{p}=1.5-2.5 \mathrm{~m}$

pier (b)

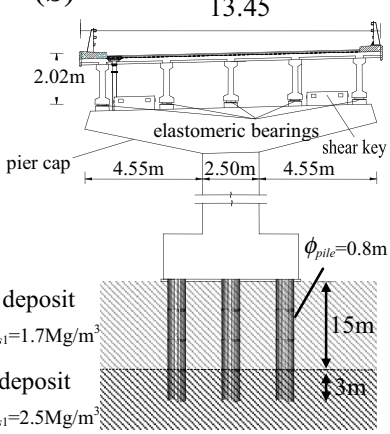

Fig. 2 The benchmark bridge: a longitudinal section, $\mathbf{b}$ transverse section at pier 
The piers are circular solid sections with diameter $D_{p}=2.5 \mathrm{~m}$. The height of the pier $H_{p}$ is equal to $10 \mathrm{~m}$. The cap beam of the pier has a depth of $1.5 \mathrm{~m}$. The longitudinal dimension of the cap beam is equal to the diameter of the pier plus $0.5 \mathrm{~m}$, the transverse dimension is $5 \mathrm{~m}$. The longitudinal pier reinforcement consists of 93 rebars of diameter $26 \mathrm{~mm}$, whereas the transverse reinforcement consists of rebars of $14 \mathrm{~mm}$ with a spacing of $100 \mathrm{~mm}$. The class of the concrete is C30/40 whereas the class of steel is S355.

The foundations of the bridge piers consist of $3 \times 3$ piles and the soil profile consists of a deformable soil layer overlying a very dense sand deposit. The soil type is classified as $\mathrm{C}$ according to EC8-1 (2005), corresponding to a soil factor $S=1.15$ and the peak ground acceleration (PGA) expected at the site is $\mathrm{PGA}=0.4 \mathrm{Sg}$, where $g$ denotes the gravity constant.

\subsection{Finite element model of the benchmark bridge}

A three-dimensional finite element model (FEM) of the benchmark bridge is built in OpenSees (McKenna et al. 2006) by following the guidelines of Kappos et al. (2012). Figure 3 a shows the connectivity and some properties of the elements used to develop the FEM.

The superstructure and the piers are modelled by a spine of linear beam-column elements with lumped nodal masses, spanning between successive nodes along the elements length. The spine represents the geometrical centre of the modelled structural components. The prestressed deck is modelled by linear elastic frame elements with uncracked stiffness properties, whereas the piers are modelled by linear elastic frame elements with cracked effective stiffness properties evaluated based on the moment-curvature analysis of the base section under the axial force induced by the permanent loads. The effective cracked stiffness (secant to the yielding point) is $50 \%$ of the gross stiffness and it is described in the model by reducing the second moment of area of the transverse pier section. The value of the bending moment demand is monitored during the analysis to check whether the yield strength of the piers is exceeded or not. A set of lumped parameter models (LPMs), as shown in Fig. 3b, is used to describe the soil-structure inertial interaction between the soil and the foundations (Makris et al. 1994; Dezi et al. 2013; Lesgidis et al. 2015), as discussed more in detail in the next section. The Young's modulus of the reinforced concrete piers and of the deck is assumed equal to 30GPa. The viscous damping of the system, which represents the energy dissipation sources other than that of the isolators, is taken into

(a)

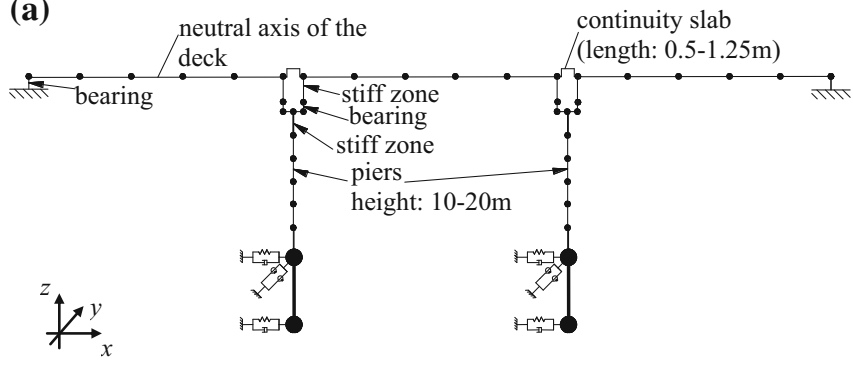

(b)

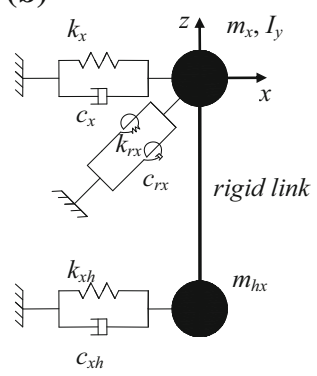

Fig. 3 a Description of the FE model of the isolated bridge analysed, b detail of the lumped parameter model for soil-structure-interaction effects 
account through the "region command", i.e. by assigning a Rayleigh damping to the piers nodes. The parameters of the Rayleigh damping model are evaluated by considering a damping ratio of $5 \%$ in correspondence of the vibration frequencies of the two higher modes which involve the flexure of the piers in the longitudinal direction. In the reference bridge configuration and for the fixed base condition, these circular vibration frequencies are $50.3 \mathrm{rad} / \mathrm{s}$ and $241.0 \mathrm{rad} / \mathrm{s}$.

\subsection{High damping rubber isolators model description}

The isolators are described by employing the high damping rubber (HDRB) model developed by Kumar et al. (2014). This model consists of a two-node, twelve degrees-offreedom discrete element, where the two nodes are connected by six springs representing the mechanical behaviour along the six main degrees of freedom of the bearing. The HDRB element permits to accurately describe both the nonlinear amplitude-dependent behaviour in shear of the isolator and the vertical (tensile or compressive) behaviour, as well as the coupling between the horizontal and vertical responses.

The shear behaviour of the bearing in the horizontal plane is described by the model proposed by Grant et al. (2004). The HDRB model parameters for this behaviour are calibrated against displacement-controlled double-shear tests carried out at TARRC on a previously scragged rubber compound commonly employed for seismic isolation. The test was carried out by imposing cycles at increasing strain amplitudes and constant strain rate of $2 / \mathrm{s}$, corresponding to a vibration period between 2 and $3 \mathrm{~s}$ for strain amplitudes in the range between 100 and $200 \%$. Figure $4 \mathrm{a}$ shows the imposed strain history whilst Fig. 4b shows the comparison between the test results and the response simulated using the Grant's et al. (2004) model for the behaviour of rubber in shear.

The axial (i.e., vertical) stiffness $K_{v}$ of the HDRB model is obtained from the two-spring model of Koh and Kelly (1987), which has been validated experimentally by Warn et al. (2007). The coupling of horizontal and vertical behaviour is due to: (1) the variation of the shear stiffness with axial load and (2) the dependence of axial stiffness on the magnitude of the lateral displacement (Kumar et al. 2014). The shear stiffness reduces progressively for compressive axial loads approaching the critical buckling load. The value of the latter is considered to decrease as the bearing effective area, i.e., the overlapping area between the
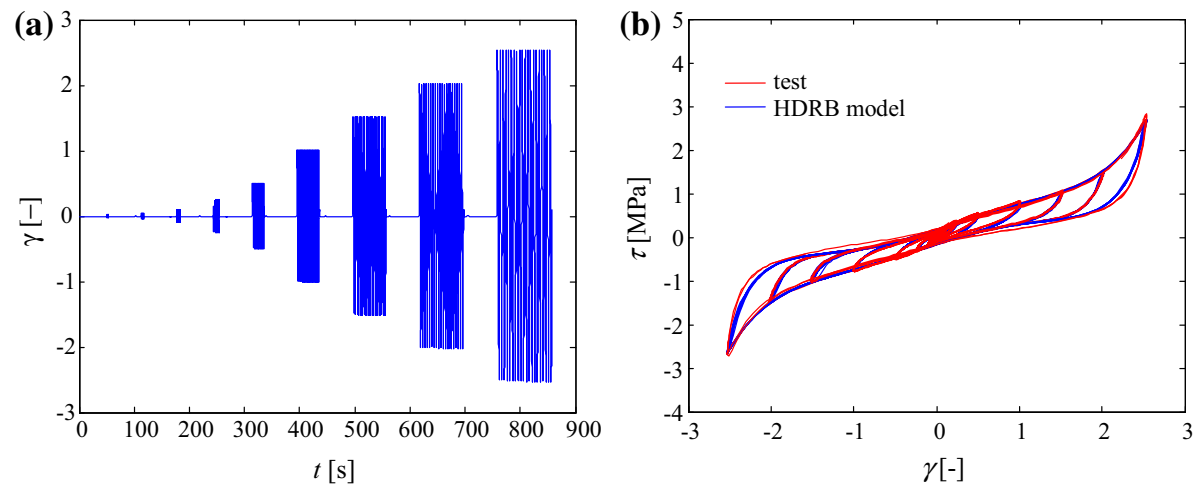

Fig. 4 a Strain pattern imposed on the bearing during the laboratory tests, $\mathbf{b}$ comparison between test results and simulated results 
top and bottom internal plates, reduces, but, in first approximation, a residual buckling resistance of the bearing at zero overlap area is considered (Kumar et al. 2014). Also, the vertical stiffness of the isolator reduces with increase in the horizontal displacement. It is worth pointing out that the large lateral displacements experienced by the isolators, corresponding to shear strains of the order of 100-200\%, can potentially lead to substantial reductions in the vertical load-carrying capacity and the vertical stiffness of the HDRB bearings (Cardone and Perrone 2012), and the employed bearing model is capable of reproducing this behaviour.

With regards to the behaviour of the bearings under tension, prior to the cavitation of the elastomer, the vertical stiffness of a steel-laminated rubber bearing is the same as that in compression. The onset of cavitation occurs for tensile stresses of $3 G_{\text {eff }}$, where $G_{\text {eff }}$ is the effective shear modulus. The torsional behaviour as well as the rotational behaviour are described by a linear elastic model. Table 1 provides the parameters of the HDRB model employed for the analysis whereas Table 2 provides the period, modal participation mass factor (MPMF), and shape of the most relevant vibration modes of the reference bridge model.

\subsection{Seismic input description and modelling of the soil-structure interaction effects}

The seismic input is described by the EC8-1 (2005) soil type C spectrum for a PGA of $0.4 \mathrm{~g}$ and soil type $\mathrm{C}$. The seismic assessment of the bridge is performed by carrying out non-linear time history analyses of the structure under a set of seven natural records describing the record-to-record variability effects. This set of ground motion records is compatible with the response spectrum considered for the design and has been selected by using the software Rexel v3.5 (Iervolino et al. 2010). The vertical component of the earthquake, albeit important for the safety evaluation of the isolators, was not studied thoroughly in this paper, as emphasis was placed on the evaluation of the effects of the coupled horizontal-vertical behaviour on the axial force demand in the bearings as observed due to horizontal excitation only.

Figure 5 shows the pseudo-acceleration and displacement spectra of the seven ground motion records and the mean spectra for the damping ratio $\xi_{i s}=10.8 \%$, which is the HDNR equivalent damping ratio at the design shear strain $\gamma_{i s}=1.5$.

With regards to the soil-structure interaction (SSI) effects, LPMs placed at the base of the piers describe the inertial SSI effects (Fig. 3b). These LPMs consist of a set of translational and rotational springs, dampers and masses that permit simulation of the frequency-dependent compliance of the soil-foundation system for analyses in the time domain. It is noteworthy that this study does not account for the kinematic effects on the foundation input motion and thus the free-field motion can be directly used as the input motion. Since isolated bridges are expected to be excited by relatively low frequencies, the

Table 1 Parameters of the HDRB model in OpenSees (McKenna et al. 2006) for the reference bridge case

\begin{tabular}{|c|c|c|c|c|c|c|c|}
\hline$\overline{G_{e f f}\left(\mathrm{kN} / \mathrm{m}^{2}\right)}$ & $K_{\text {bulk }}\left(\mathrm{kN} / \mathrm{m}^{2}\right)$ & $a_{1}(\mathrm{kN} / \mathrm{m})$ & $a_{2}\left(\mathrm{kN} / \mathrm{m}^{3}\right)$ & $a_{3}\left(\mathrm{kN} / \mathrm{m}^{5}\right)$ & $b_{1}(\mathrm{kN} / \mathrm{m})$ & $b_{2}\left(1 / \mathrm{m}^{2}\right)$ & $b_{3}(1 / \mathrm{m})$ \\
\hline 700 & $2,000,000$ & 646.485 & -3586.12 & 24015.72 & 30.69 & 402.96 & 32.65 \\
\hline$c_{1}\left(1 \mathrm{~m}^{-3}\right)$ & $c_{2}\left(1 \mathrm{~m}^{-3}\right)$ & $c_{3}(-)$ & $c_{4}\left(1 \mathrm{~m}^{-3}\right)$ & $K_{c}(-)$ & $f_{M}(-)$ & \multicolumn{2}{|c|}{$a_{c}(-)$} \\
\hline 0 & 0 & 1 & 0 & 0.02 & 0.5 & 1 & \\
\hline
\end{tabular}


Table 2 Period, modal participation mass factor (MPMF), and shape of most relevant vibration modes

\begin{tabular}{lllll}
\hline No\# & Period (s) & Direction & MPMF $(\%)$ & Mode shape \\
\hline 1 & 2.02 & Longitudinal deck displacement & 78.6 \\
2 & 0.28 & Vertical deck displacement & 17.7 \\
4 & Vertical deck displacement & 47.8 \\
5 & & & \\
& & & \\
& & &
\end{tabular}
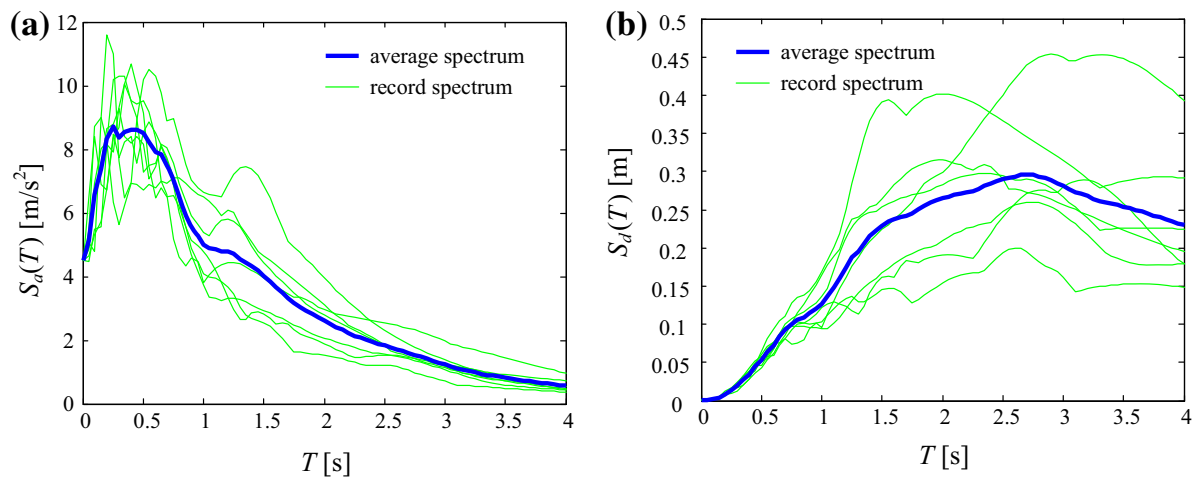

Fig. 5 Spectra of ground motion records and mean spectra for $10.8 \%$ damping ratio: a pseudo-acceleration response spectra; b displacement response spectra

error resulting from neglecting the kinematic SSI effects is expected to be negligible (Dezi et al. 2013; Olmos and Roesset 2012; Ucak and Tsopelas 2008).

The properties of the LPMs are derived by employing the approach outlined by Dezi et al. (2013), based on simplified formulae calibrated from results of extensive non-dimensional parametric analyses considering head-bearing pile groups. The proposed approach allows accurately simulation of the compliance of pile foundations and important features of the soil-foundation system behaviour, such as the coupled rotational-translational response. The properties of the LPMs are consistent with the considered soil type and the geometrical and mechanical properties of the foundation. The piles are fully embedded in the soil, socketed into the sand deposit and connected at the heads by a cap (Fig. 2b). The concrete piles have a Young's modulus of $30 \mathrm{GPa}$ and a density of $2.5 \mathrm{ton} / \mathrm{m}^{3}$. They have a length of $18 \mathrm{~m}$, with circular cross sections of $0.8 \mathrm{~m}$ diameter and a spacing of three diameters (center to center). The deformable deposit has a depth of 
$15 \mathrm{~m}$, a shear wave velocity $V_{s 1}=200 \mathrm{~m} / \mathrm{s}$ and a density $\rho_{s 1}=1.7 \mathrm{ton} / \mathrm{m}^{3}$. The dense sand deposit has shear wave velocity $V_{s 2}=800 \mathrm{~m} / \mathrm{s}$ and density $\rho_{s 2}=2.5 \mathrm{ton} / \mathrm{m}^{3}$. Poisson's ratio is considered to be $v_{s}=0.4$ and material hysteretic damping $\xi_{s}=10 \%$, which is compatible with the design level of strain in the soil.

The impedance matrix $\tilde{\Xi}(\omega)$ corresponding to the proposed LPM is expressed in the form:

$$
\tilde{\Xi}(\omega)=\tilde{\mathbf{K}}-\omega^{2} \tilde{\mathbf{M}}+i \omega \tilde{\mathbf{C}}
$$

where $\tilde{\mathbf{K}}, \tilde{\mathbf{M}}$, and $\tilde{\mathbf{C}}$ are frequency independent stiffness, mass and damping matrices whose parameters are calibrated by employing the procedure reported in Dezi et al. (2013). Having considered a seismic input along the bridge longitudinal direction, the bridge exhibits a non-null response in the longitudinal direction and only some components of the impedance matrix $\tilde{\Xi}(\omega)$ are significant for the problem studied. In particular, the real and imaginary part of the translational component of the matrix $\tilde{\Xi}(\omega)$ are equal to $1.26 \mathrm{E}+06$ and $7.26 \mathrm{E}+04 \mathrm{kN} / \mathrm{m}$, those of the rotational component are equal to $4.84 \mathrm{E}+07$ and $4.00 \mathrm{E}+05 \mathrm{kNm}$, those of the coupled rotational-translation component are equal to $1.57 \mathrm{E}+06$ and $6.20 \mathrm{E}+04 \mathrm{kN}$, and those of the vertical translational component are equal to $7.49 \mathrm{E}+06$ and $2.17 \mathrm{E}+05 \mathrm{kN} / \mathrm{m}$.

\section{Parametric study}

This section investigates the likelihood of the occurrence of bearing uplift, buckling, or of other relevant limit states, as prescribed in the Appendix of this paper, for the bridge configuration under consideration. First, the reference bridge model is analysed in detail to show some important features of the bridge response. In particular, the following response parameters are monitored, since they provide information useful to assess the performance of the bridge components: (a) the isolator translational and rotational deflections and forces along the horizontal and vertical directions; (b) the internal actions on the piers; (c) the displacements and the rotations of the pier cap with respect to the ground; (d) the horizontal and vertical displacements and rotations of the deck with respect to the ground; (e) the displacements and rotation of the continuity slab with respect to the ground. Particular emphasis is placed on the response of the isolators, which mainly depends on the displacements and rotations of the deck and the pier cap.

Successively, an extensive parametric study is carried out to evaluate the performance of a set of realistic bridge models obtained by varying critical design parameters of the reference model, which are related to the properties of the superstructure, the substructures and the isolators. The aforementioned critical design parameters were defined based on a preliminary sensitivity analysis, which has identified which design choices influence significantly the bearing vertical response.

Then, analyses are carried out for two different load combinations, i.e. the ultimate limit state (ULS) combination for non-seismic actions and the seismic design combination corresponding to the earthquake input described previously. The adequacy of the isolation system to sustain the design loads is assessed on the basis of the checks provided in EN1337-3 (2005) for the ULS design combination of actions, EN15129 (2009) and EC8-2 (2005) for the seismic load combinations.

The code prescriptions that need to be satisfied by the bearings are given in the Appendix of this paper. These prescriptions are expressed in the form of inequalities based 
upon demand-to-capacity ratios $(D / C)$, where the demand is the value of the response parameter of interest for the limit state being monitored, evaluated by structural analysis, whilst the capacity is the maximum allowable value for the relevant parameter, as prescribed by the codes. It is noteworthy that in calculating the $D / C$ ratios, the mean value of the peak response parameters obtained for the seven natural seismic motions considered are used. A value of the ratio higher than one, i.e. $D / C>1$, implies that the limit state is not satisfied, whereas a value less than 1 implies that that the design satisfies the relevant code requirement.

In addition to the assessment of the bearing performance, the performance of the piers is monitored to make sure that they do not yield under the combination of the axial loads and bending moments and that the shear demand does not exceed their shear capacity.

It is noteworthy that for all bridge models investigated, the isolation bearing system is designed through the procedure outlined in the following section to achieve a target period of $2.0 \mathrm{~s}$. This value is significantly higher than the value of $0.46 \mathrm{~s}$ corresponding to the fixed-base configuration.

\subsection{Procedure for the design of the isolation system}

Figure 6 describes the procedure followed for the design of the isolation system. The procedure starts by fixing a target value of the nominal isolated bridge period $T_{i s}$, from which the individual secant stiffness $K_{i s}$ of each of the $n_{i s}$ isolators can be calculated under the assumption that the piers and the foundation-soil system are infinitely rigid. This simplified procedure is particularly convenient because it yields a simple closed-form estimate of the required bearing stiffness. It results in the same bearing properties for tall and short piers. Although the influence of the substructure flexibility on the stiffness of the composite foundation-pier-isolator system could be included in the proposed procedure (e.g., Cardone et al. 2009; Tubaldi and Dall'Asta 2011), it is neglected in the design phase, while its effects on the bridge seismic response are investigated only in the parametric study.

In the second step, the design displacement $d_{E d}$ is calculated based on the damped mean record spectrum as given in Fig. 5a for the records considered in this study. In the third step, for a fixed value of the shear strain $\gamma_{E d}$ the total thickness of the elastomer $T_{r}$ is calculated. The bearing area $A_{r}$ and diameter $D_{r}$ can also be computed based on the knowledge of the rubber shear effective modulus $G_{\text {eff }}$ at the design shear strain $\gamma_{E d}$. The last step of the procedure involves fixing the value of the shape factor of the isolator $S_{r}$, denoting the ratio between the loaded area and the force-free area for a circular bearing of diameter $D_{r}$. This provides the thickness $t_{r}$ and the number $n_{r}$ of the rubber layers in each bearing.
1) Fix $T_{i s}$
2) Damped displacement spectrum
3) Fix $\gamma_{E d}$

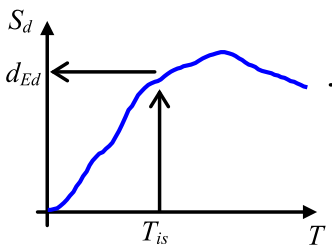
$T_{r}=\frac{d_{E d}}{\gamma_{E d}}$
$A_{r}=\frac{K_{i s} T_{r}}{G_{e f f}}$
$D_{r}=\sqrt{\frac{4 A_{r}}{\pi}}$
4) Fix $S_{r}$
$t_{r}=\frac{D_{r}}{4 S_{r}}$
$n_{r}=\operatorname{int}\left(\frac{T_{r}}{t_{r}}\right)+1$
$T_{r, \text { new }}=n_{r} t_{r}$

Fig. 6 Flowchart for the design of the isolators 
The parameters $T_{i s}, T_{r}$, and $S_{r}$, the mechanical (effective) properties of the bearings, $G_{\text {eff }}$ and $\xi_{i s}$, and the seismic input spectral ordinate $S_{d}\left(T_{i s}\right)$ define unequivocally the geometry of the isolation bearings with the exception of some parameters such as the thickness of the steel plates and of the side cover layer of rubber for which additional design rules are given in the codes. In particular, values of the thickness of the steel plates significantly higher than the minimum value required to avoid steel yielding are chosen, since very flexible plates have been found to affect significantly the stability of the bearings (Muhr 2006, 2007).

The design procedure employed in this study is not intended to cover all the aspects related to the bearing design and may lead to bearing properties not consistent with those available in manufacturer catalogues. Although alternative design procedures and criteria could have been employed for the design (e.g. Cardone et al. 2009, 2010), the proposed one was chosen for its simplicity, as it requires no iterations and also allows to obtain and control directly all the properties required for the calibration of the HDNR bearing model.

\subsection{Seismic response of the reference bridge with emphasis on the response of the bearings}

The geometry of the reference bridge considered for the in-depth analysis of the seismic response is described by the following parameters: span length $L_{s p}=30 \mathrm{~m}$, pier height $H_{p}=10 \mathrm{~m}$, cap beam height $H_{c b}=1.35 \mathrm{~m}$, bearing eccentricity $e_{b}=0.8 \mathrm{~m}$, continuity slab length $L_{c s}=0.5 \mathrm{~m}$. The design of the bearing is carried out by following the procedure outlined above for a target vibration period of $T_{i s}=2.0 \mathrm{~s}$, corresponding to a displacement demand in the fundamental mode of vibration of $0.264 \mathrm{~m}$ and a damping ratio $\xi_{i s}=10.8 \%$. The initial value of the design shear deformation under the seismic input is $\gamma_{E d}=1.5$. For the assumed effective shear modulus $G_{e f f}=700 \mathrm{kPa}$, this corresponds to bearings with a total rubber height $T_{r}=176 \mathrm{~mm}$ and a rubber diameter $D_{r}=490 \mathrm{~mm}$. The value of the bearing shape factor is $S_{r}=15$, leading to a thickness of single rubber layer of $t_{r}=8 \mathrm{~mm}$, and number of rubber layers $n_{r}=22$. The assumed value of the shim plate thickness is $t_{s}=5 \mathrm{~mm}$.

The material, geometric and mechanical properties of the elastomeric bearings for this reference bridge configuration are reported in Table 3; calculations of properties from the primary parameters have been carried out in accordance with the formulae reported in Kumar et al. (2014). Reference has been made to Kelly (1997) for the evaluation of the critical buckling load and adjusted (effective) bearing geometrical properties, and to Warn et al. (2007), with reference mainly to the horizontal-vertical behaviour interaction.

Figure 7 reports the time history of the deck horizontal displacement, $d_{h d}$, and of the pier cap displacement, $d_{h p}$, for the first record (\#1) considered in this study. This figure shows that the piers are efficiently isolated as the pier displacement is significantly smaller than the deck displacement. The mean value of the deck displacement, obtained by averaging the results for the seven records, is $0.280 \mathrm{~m}$, whereas the design value is $0.264 \mathrm{~m}$, i.e. a relative deviation of $5 \%$ was obtained. The difference between the design value and the mean value obtained from the analysis is the effect of (1) the pier dynamics, (2) the nonlinear behaviour of the rubber and (3) the moment developed at the top of the piers due to the axial forces of the bearings, which influence the pier boundary conditions. The time history of the deck displacement is characterised by a fundamental period of approximately $2.0 \mathrm{~s}$, which is the design period, whereas the time history of the pier displacement is characterised by a higher frequency content, since its is influenced by higher vibration modes of the piers. 
Table 3 Bearing material, geometric, and mechanical properties for reference bridge

\begin{tabular}{lclr}
\hline Diameter $D[\mathrm{~m}]$ & 0.4908 & Moment of inertia of bearing $I\left[\mathrm{~m}^{4}\right]$ & 0.0030 \\
Bearing cover $t_{c}[\mathrm{~m}]$ & 0.0050 & Adjusted moment of inertia $I_{s}\left[\mathrm{~m}^{4}\right]$ & 0.0047 \\
Rubber thickenss $t_{r}[\mathrm{~mm}]$ & 0.0082 & Adjusted shear area $A_{s}\left[\mathrm{~m}^{2}\right]$ & 0.3057 \\
Steel thickenss $t_{s}[\mathrm{~mm}]$ & 0.0050 & Compressive modulus $E_{c}\left[\mathrm{kN} / \mathrm{m}^{2}\right]$ & $579,754.6$ \\
Number of rubber layers $[-]$ & 22 & Rotational modulus $E_{r}\left[\mathrm{kN} / \mathrm{m}^{2}\right]$ & $193,251.5$ \\
Effective shear modulus $G_{e f f}\left[\mathrm{kN} / \mathrm{m}^{2}\right]$ & 700 & Initial vertical stiffness $K_{v 0}[\mathrm{kN} / \mathrm{m}]$ & $621,960.7$ \\
Bulk modulus of rubber $K\left[\mathrm{kN} / \mathrm{m}^{2}\right]$ & $2,000,000$ & Cavitation force $F_{c}[\mathrm{kN}]$ & 405.4 \\
External diameter $D_{e}[\mathrm{~m}]$ & 0.4958 & Euler buckling load $P_{e}[\mathrm{kN}]$ & $110,316.2$ \\
Total rubber height $T_{r}[\mathrm{~m}]$ & 0.1800 & $P_{s}=G_{e f f} \mathrm{~A}_{s}[\mathrm{kN}]$ & 213.991 \\
Total bearing height $h[\mathrm{~m}]$ & 0.2850 & Critical buckling load $P_{c r}[\mathrm{kN}]$ & 4858.67 \\
Shear area $A_{s}\left[\mathrm{~m}^{2}\right]$ & 0.1931 & Rotational stiffness $K_{r}[\mathrm{kNm}]$ & 5043.5 \\
Shape factor $S_{r}[-]$ & 15.000 & Initial horizontal stiffness $K_{h 0}[\mathrm{kN} / \mathrm{m}]$ & 751.0 \\
\hline
\end{tabular}

Figure 7 also reports the time histories of the deck and the pier cap displacements obtained by neglecting SSI effects, i.e., by considering a fixed base condition. SSI effects influence significantly only the pier displacement demand. In fact, the maximum pier top displacement obtained when accounting for SSI effect is $0.032 \mathrm{~m}$ and thus it is significantly higher than the $0.020 \mathrm{~m}$ value obtained for the fixed-based condition.

Table 4 reports the maximum absolute values of the displacement of the deck, $d_{h d \text {, max }}$, of the displacement of the pier cap, $d_{h p \text {, max }}$, and of the rotation of the pier cap $r_{p \text {, max }}$, evaluated by accounting for and by neglecting SSI effects. In the table, both the maximum and the mean value obtained for the different records are provided. It can be observed that SSI effects influence significantly the demand of the pier displacement and of the pier rotation, which increase by 48 and $23 \%$ with respect to the fixed base case. On the contrary, the effect of SSI on the deck displacement demand is negligible, since the average displacement increases only by $2 \%$.

Figure 8 shows the time history of the rotation of the bearing $r_{b, 1}$ and of the deck at the first line of support $r_{d, 1}$ over the first (i.e., left) pier for record \#1. The initial value of the bearing rotation, which is negative because of the assumed reference system, is the value of
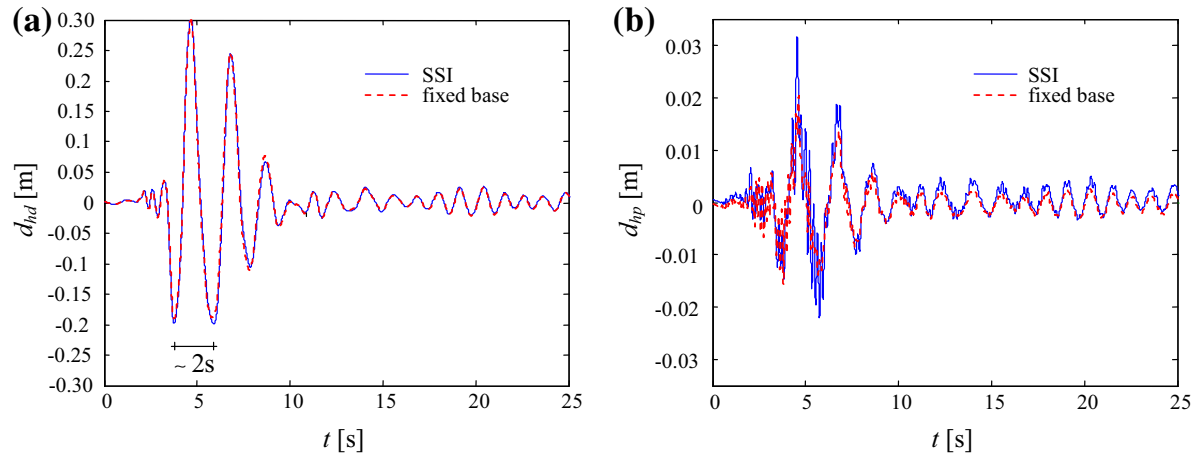

Fig. 7 Time history of the displacement with respect to the ground of $\mathbf{a}$ the deck and $\mathbf{b}$ the pier cap obtained by accounting for or disregarding SSI effects for record \#1 
Table 4 Influence of SSI effects on deck and pier and response

\begin{tabular}{|c|c|c|c|c|c|c|}
\hline \multirow[t]{2}{*}{ Record } & \multicolumn{3}{|c|}{ SSI } & \multicolumn{3}{|c|}{ Fixed base } \\
\hline & $d_{h d, \max }(\mathbf{m})$ & $d_{h p, \max }(\mathbf{m})$ & $r_{p, \max }(\mathrm{rad})$ & $d_{h d, \max }(\mathbf{m})$ & $d_{h p, \max }(\mathbf{m})$ & $r_{p, \max }(\mathrm{rad})$ \\
\hline$\# 1$ & 0.309 & 0.032 & 0.003 & 0.303 & 0.020 & 0.003 \\
\hline \#2 & 0.211 & 0.025 & 0.003 & 0.202 & 0.020 & 0.003 \\
\hline \#3 & 0.148 & 0.017 & 0.002 & 0.148 & 0.009 & 0.001 \\
\hline \#4 & 0.335 & 0.031 & 0.004 & 0.329 & 0.024 & 0.003 \\
\hline$\# 5$ & 0.173 & 0.016 & 0.002 & 0.171 & 0.013 & 0.002 \\
\hline \#6 & 0.317 & 0.036 & 0.004 & 0.312 & 0.021 & 0.003 \\
\hline \#7 & 0.463 & 0.064 & 0.008 & 0.460 & 0.041 & 0.006 \\
\hline Average & 0.280 & 0.031 & 0.004 & 0.275 & 0.021 & 0.003 \\
\hline
\end{tabular}
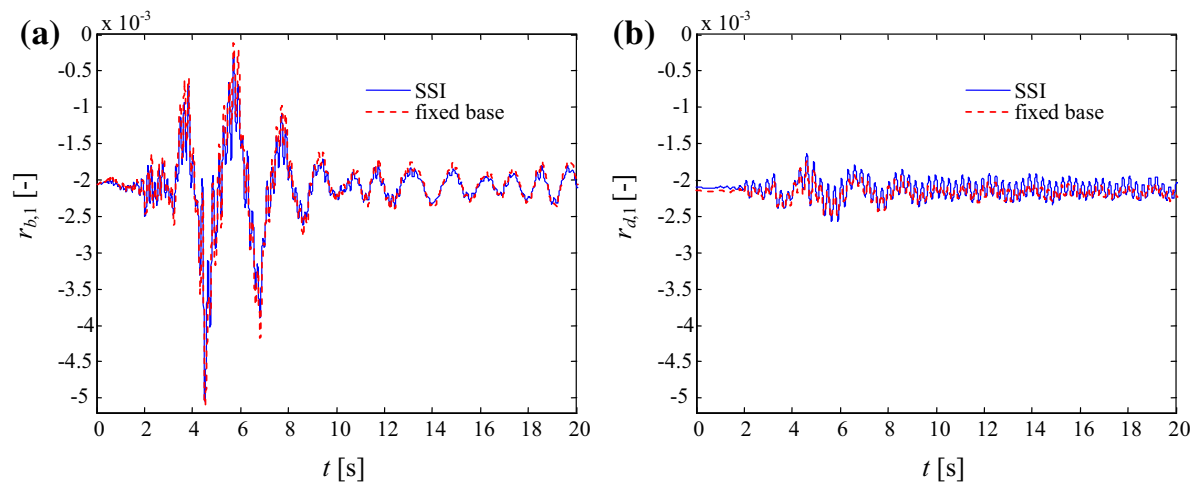

Fig. 8 Time history of a rotation of the bearing at the first line of support, $\mathbf{b}$ rotation with respect to the ground of the deck node over the bearings at the first line of support for record \#1

the rotation induced by the vertical loads acting on the deck. During the seismic motion, the pier rotation provides the major contribution to the bearing rotation, whereas the contribution due to the rotation of the deck (Fig. 8b) is quite low. Similar results can be observed for the bearings at the second line of support.

Figure 9 shows the hysteretic shear and axial responses of two bearings placed respectively on the first and second line of support above the first pier, for record \#1 of the set. The responses of the two bearings under shear loading (Fig. 9a) are similar and they are characterised by an increase of hysteresis for increasing shear deformations, which is typical of HNDR material behaviour. On the contrary, the responses along the vertical direction (Fig. 9b) are quite different for the bearings on the left and the right lines of support. This is the consequence of the fact that the bearing vertical behaviour is highly nonlinear and that the seismic action induces forces of opposite signs in the two bearings. Furthermore, the initial value of the compressive force is different for the two bearings ( $820 \mathrm{kN}$ for the bearing at the first line of support, and $715 \mathrm{kN}$ for the bearing at the second line of support, corresponding to an axial displacement of 1.3 and $1.1 \mathrm{~mm}$ and compressive pressures of 4.3 and 3.8 MPa respectively). It is noteworthy that these initial compression loads prevent the cavitation of the rubber for this particular case-study. It is also interesting 
to observe in Fig. 9b that for both the lines of support, the horizontal response influences the vertical behaviour and induces a significant reduction of the vertical stiffness. However, the values of the compressive axial forces during the time history remain significantly lower than the buckling load, which is equal to $4858.7 \mathrm{KN}$ at zero horizontal displacement, and to $2476.5 \mathrm{kN}$ at the maximum horizontal displacement of $0.30 \mathrm{~m}$.

In order to provide further information on the vertical response of the isolators, the time history of the axial deflection of the bearings $d_{v b, 1}$ along the first line are plotted in Fig. 10a. Obviously, the motion of the bearings is characterised by oscillations around the initial value corresponding to the compression due to the vertical loads acting on the deck. Moreover, the amplitude of the positive axial displacement that causes tension in the isolators is significantly inferior to the amplitude of the negative, i.e. compressive, axial displacement, which increases the compression due to vertical loads. This is mainly due to the reduction of the vertical stiffness in compression, which is relevant when the compressive load approaches the buckling load (Kumar et al. 2014).
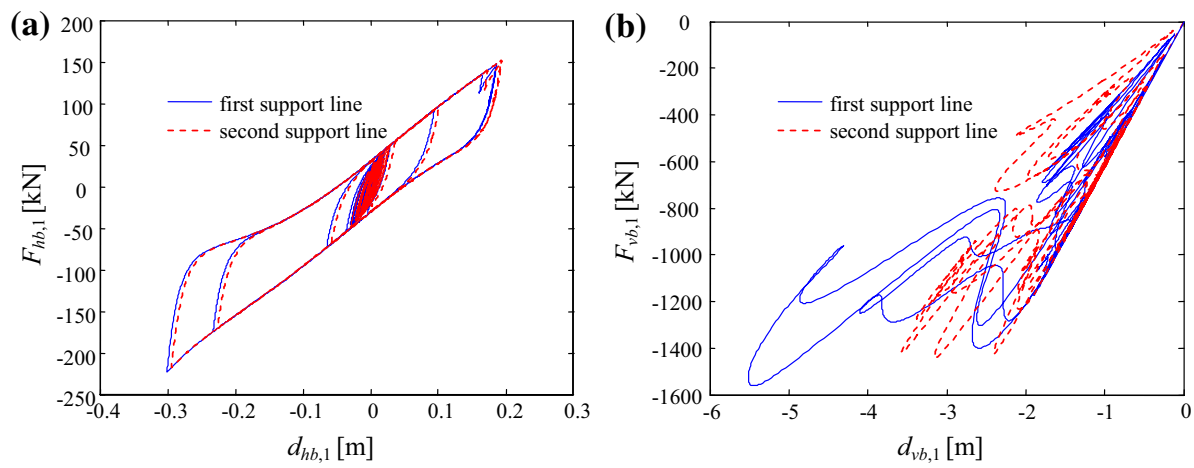

Fig. 9 Hysteretic response of bearings under record \#1 in a shear and $\mathbf{b}$ along the vertical direction. $\mathrm{d}_{h b, \mathrm{i}}=$ horizontal deflections, $F_{h b, \mathrm{i}}=$ horizontal forces, $\mathrm{d}_{v b, \mathrm{i}}=$ vertical deflections, $F_{v b, \mathrm{i}}=$ vertical forces, $i=1,2$ denote the two bearing lines
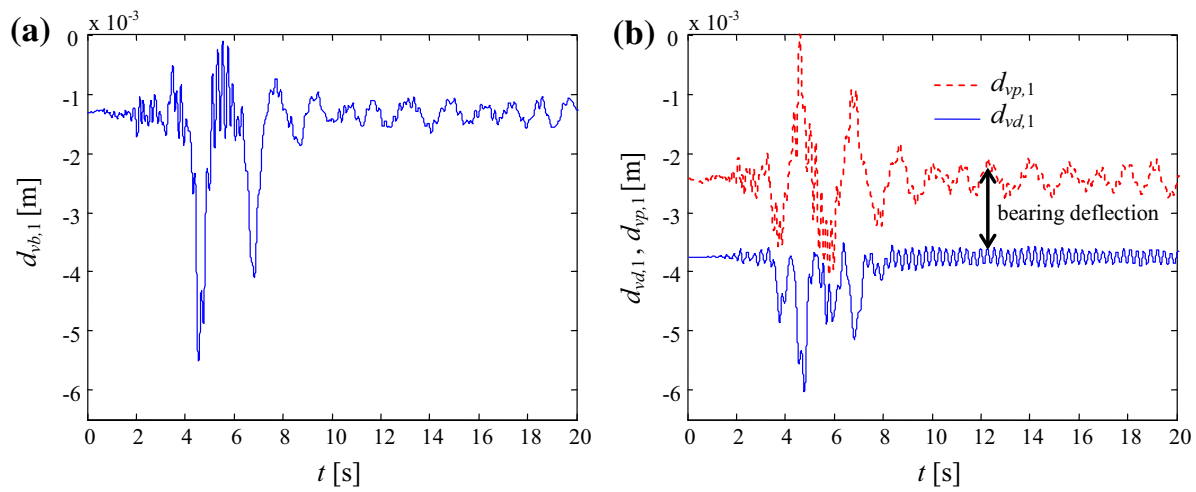

Fig. 10 Time histories of $\mathbf{a}$ the axial deflection of the bearing and $\mathbf{b}$ the vertical displacements relative to the ground of the top and bottom nodes connected by the HDNR bearing element at the first line of support under record \#1 
Figure 10b compares the time histories of the vertical displacements of the top and bottom nodes connected by the HDNR bearing element at the first support line, respectively denoted to as $d_{v d, 1}$ and $d_{v p, 1}$ and representing the vertical motion of the deck and the pier cap. The motion of the bottom node can also be obtained as the pier cap rotation times the bearing eccentricity, i.e., $d_{v p, 1=} r_{p} \cdot e_{b}$.

It can be seen in Fig. 10b that although the axial bearing deflection is mainly controlled by the pier rotation, it is also influenced by the deck motion, since $d_{v b, 1}=d_{v d, 1}-d_{v p, 1}$. It is also noteworthy that both these vertical displacements are developed due to the horizontal seismic actions only, as no vertical component of the seismic action is considered in this study.

Since the axial bearing response is influenced by the pier rotation, which in turn is strongly affected by SSI effects, it is interesting to evaluate also the influence of SSI effects on the axial deflections of the bearings at the first and second line of supports, denoted respectively by $d_{v b, 1}$ and $d_{v b, 2}$. Table 5 reports the maximum (max) and minimum (min) of these response quantities for the different records as well as the average values.

On average, the SSI effects are found to induce an increase of the absolute values of the bearing axial deflection demand. This highest relative increase is about $40 \%$ for the maximum deflection, and of $24 \%$ for the minimum deflection. Similar observation can be drawn for the bearing axial forces, not reported due to space constraint.

\subsection{Influence of shape factor on pier response and bearing capacity}

Based on the results of the analysis of the reference bridge model, it is evident that there is a strong coupling between the horizontal and the vertical response of the isolators, as a result of the eccentricity of the bearings and of their axial stiffness, which results in a force couple, i.e. a bending moment forming at the pier top. Since for a given target design period and, thus, for a given bearing translational stiffness the parameter that governs the vertical behaviour and capacity is the shape factor $S_{r}$ of the isolator, the benchmark bridge is re-analysed for values of the shape other than the value 15 employed for the reference case. The rest of the bridge properties and bearing design parameters are kept constant and equal to the reference values. Smaller shape factors correspond to axially and rotationally

Table 5 Influence of SSI effects on bearing axial displacements

\begin{tabular}{|c|c|c|c|c|c|c|c|c|}
\hline \multirow[t]{2}{*}{ Record } & \multicolumn{4}{|c|}{ SSI } & \multicolumn{4}{|c|}{ Fixed-base } \\
\hline & $\begin{array}{l}d_{v b 1, \max } \\
(\mathrm{mm})\end{array}$ & $\begin{array}{l}d_{v b 1, \min } \\
(\mathrm{mm})\end{array}$ & $\begin{array}{l}d_{v b 2, \max } \\
(\mathrm{mm})\end{array}$ & $\begin{array}{l}d_{v b 2, \min } \\
(\mathrm{mm})\end{array}$ & $\begin{array}{l}d_{v b 1, \max } \\
(\mathbf{m m})\end{array}$ & $\begin{array}{l}d_{v b 1, \min } \\
(\mathrm{mm})\end{array}$ & $\begin{array}{l}d_{v b 2, \mathbf{m a x}} \\
(\mathbf{m m})\end{array}$ & $\begin{array}{l}d_{v b 2, \min } \\
(\mathrm{mm})\end{array}$ \\
\hline \#1 & -0.50 & -5.50 & -0.13 & -3.60 & -0.51 & -5.10 & -0.20 & -3.37 \\
\hline$\# 2$ & -0.18 & -4.20 & 0.14 & -2.60 & -0.47 & -4.20 & -0.06 & -2.54 \\
\hline$\# 3$ & -0.96 & -2.70 & -0.85 & -2.80 & -1.00 & -2.40 & -0.91 & -2.42 \\
\hline \#4 & -0.17 & -7.10 & -0.29 & -5.10 & -0.36 & -6.80 & -0.54 & -4.89 \\
\hline \#5 & -0.47 & -3.30 & -0.40 & -2.70 & -0.48 & -2.90 & -0.53 & -2.74 \\
\hline \#6 & 0.43 & -6.30 & 0.27 & -3.90 & 0.24 & -5.40 & -0.03 & -3.55 \\
\hline \#7 & -0.48 & -17.20 & 0.18 & -7.20 & -0.66 & -14.10 & -0.42 & -5.37 \\
\hline Average & -0.31 & -6.77 & -0.16 & -4.04 & -0.46 & -5.95 & -0.41 & $-\mathbf{3 . 5 8}$ \\
\hline
\end{tabular}




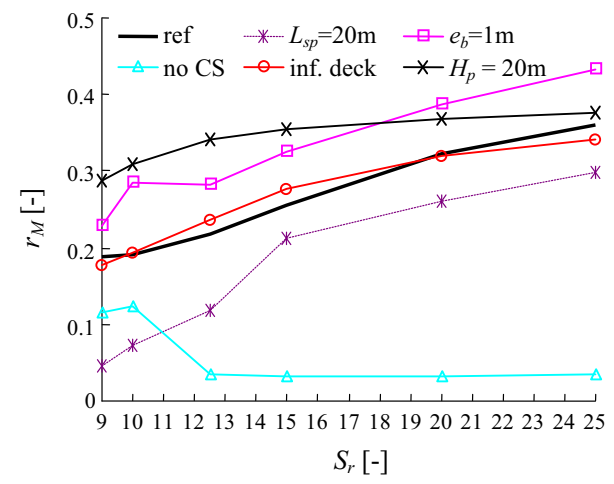

Fig. 11 Ratio of the bending moment at the top of the pier to that at the bottom vs. shape factor of the bearing $S_{r}$. The different curves refer to the reference case (ref.), to cases with lower span length $\left(L_{s p}=20 \mathrm{~m}\right)$, with higher isolator eccentricity $\left(e_{b}=1 \mathrm{~m}\right)$, with no continuity slab (no CS), with stiffer deck and continuity slab (inf. deck), and with higher pier height $\left(H_{p}=20 \mathrm{~m}\right)$, as addressed by the parametric study

flexible bearings, which are also more prone to buckling under compression, whilst the opposite is valid for larger shape factors.

In order to evaluate the influence of the shape factor on the pier boundary condition at its top, the ratio $r_{M}$ of the bending moment at the top of the pier to that at the bottom is estimated for values of $S_{r}$ ranging between 9 and 25 and plotted in Fig. 11 vs $S_{r}$. The smaller the $r_{M}$, the smaller the bending moment at the pier top, which also means that the pier rotation is not significantly restrained by the bearings. It can be observed that in general the boundary condition at the top of the pier is closer to that of a cantilever beam, corresponding to a ratio equal to zero, rather than to that of a clamped-clamped beam, corresponding to a ratio equal to 1 . However, the ratio tends to increase quite significantly for increasing values of $S_{r}$. In fact, as already pointed out, an increase of the shape factor results in an increase of the stiffness of the vertical springs representing the bearing, and thus in an increase of the stiffness of the rotational constraint provided by the eccentrically placed bearings.

The safety margin with respect to the different limit states related to the bearing performance is given by the demand-to-capacity ratios $(D / C)$ defined also in Appendix. In summary, $(D / C)_{\gamma_{\text {tot }}}$ is related to the check that the maximum local shear strain in the isolator is smaller than $7,(D / C)_{P c r}$ refers to the check of the stability under seismic actions, $(D / C)_{P c a v}$ refers to the tensile stress of the bearing that should be kept under $2 \mathrm{G}$, $(D / C)_{\gamma_{U L S}}$ refers to the design check with respect to the shear induced by the ULS load combination (Manos et al. 2012), and $(D / C)_{\alpha}$ is related to the check on the rotation limit for the bearing under the ULS load combination.

Figure 12a shows the variation of these $D / C$ ratios for values of $S_{r}$ varying in the range 9 to 25 . It can be observed that all the limit states of interest are significantly influenced by the value assumed by the shape factor $S_{r}$. For a value of $S_{r} \geq 15$, all the safety checks are satisfied, whereas small values of $S_{r}$ lead to buckling instabilities of the isolators. The $D / C$ ratios for the strains $\gamma_{b d \text {,max }}$ due to the shear only are not reported in the figure because they have been found always to be less than 1 throughout the study. 

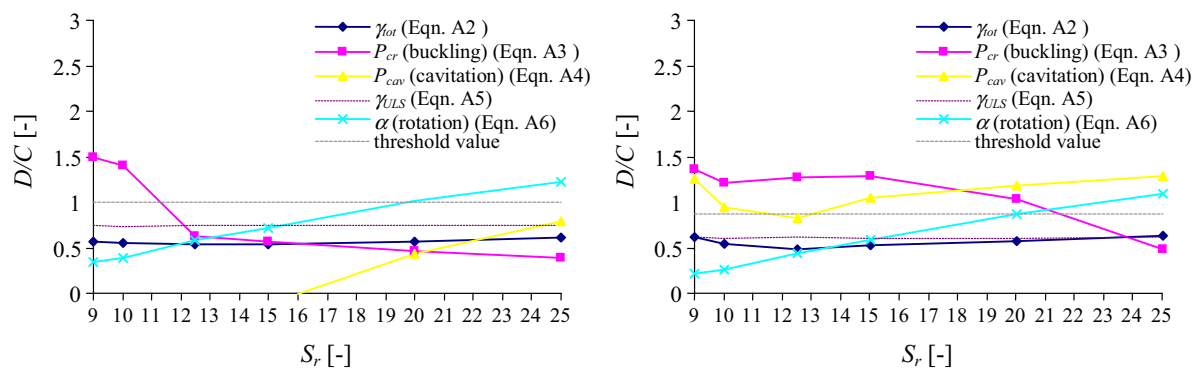

Fig. 12 Demand/Capacity ratio for different limit states vs. shape factor $S_{r}$ for the reference bridge: a horizontal component of the seismic input only, b horizontal and vertical component of the seismic input

Figure $12 \mathrm{~b}$ shows the same results obtained by considering the vertical component of the seismic excitation in addition to the horizontal longitudinal component. As expected, considering this effect results in increased values of the $D / C$ ratios corresponding to the buckling and cavitation condition.

\section{Parametric study results}

This section describes the parametric study carried out to evaluate the sensitivity of the bearing response and capacity with respect to the bridge model parameters.

In particular, the influence of the parameters describing the deck span length, the eccentricity of the isolators, the stiffness of the continuity slab, the stiffness of the deck, and the pier flexibility is investigated by observing how the $D / C$ ratios change by changing these parameters one at a time for different values of the shape factor.

\subsection{Influence of the deck-span}

In the first case analysed, the span length is assumed equal to $L_{s p}=20 \mathrm{~m}$ instead of $30 \mathrm{~m}$, whereas the values of all the other parameters are kept unchanged with respect to the reference bridge. By this way, both the total isolated mass and the bearing vertical force due to vertical loads reduce. The bearing design is carried out by assuming $T_{i s}=2 \mathrm{~s}$, $\xi_{i s}=10.8 \%, G=700 \mathrm{kN} / \mathrm{m}^{2}$ and $\gamma_{E d}=1.5$ as for the reference bridge. For $S_{r}=15$, this yields a total rubber height $T_{r}=0.18 \mathrm{~m}$, a rubber diameter $D_{r}=0.40 \mathrm{~m}$, a single rubber layer thickness $t_{r}=6.7 \mathrm{~mm}$, and a number of layers $n_{r}=27$. The shim plate thickness is again assumed as $t_{s}=5 \mathrm{~mm}$. The mean values of the pier top and deck displacement obtained through the analyses are 0.026 and $0.278 \mathrm{~m}$ respectively. The vertical pressure due to the deck weight is similar to that of the reference bridge model.

Figure 13 plots the variation with $S_{r}$ of the $D / C$ ratios. It can be observed that in this bridge configuration, for low values of the shape factor the bearings are more vulnerable to buckling and cavitation and undergo higher total strains compared to the bearings of the reference bridge. This is mainly due to the reduced bearing diameter obtained through the application of the design procedure aiming at achieving the same vibration period as in the reference case. This bearing diameter corresponds to a lower vertical resistance with respect to buckling and cavitation with respect to the reference case, and to a shear stiffness which decreases significantly during the seismic motion due to the reduction in 


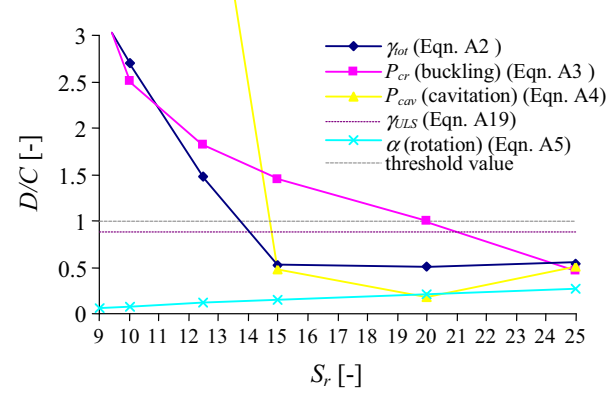

Fig. 13 Demand/Capacity ratio for different limit states versus $S_{r}$ for the case corresponding to shorter spans of length $L_{s p}=20 \mathrm{~m}$

overlapping area of the endplates. On the other hand, a higher safety factor is obtained with respect to the rotation limit state for the ULS load combination due to the reduced deck span. Furthermore, larger shape factors $(>20)$ pass all the code checks.

For a given $S_{r}$ value, the values of the moment ratio (denoted by " $L_{s p}=20 \mathrm{~m}$ " in Fig. 11) are slightly lower than the corresponding values observed in the reference case, because of the lower bearing diameter, which results in a reduced vertical stiffness. For low $S_{r}$ values, the behaviour is very close to that of a cantilever since both the horizontal and vertical stiffness of the bearings reduce significantly during the seismic action due to nonlinear geometric effects.

\subsection{Influence of the eccentricity of the isolators}

In this case, the bearing eccentricity is assumed as $e_{b}=1.0 \mathrm{~m}$ instead of $e_{b}=0.8 \mathrm{~m}$, and also the continuity slab is assumed to have a length $L_{c s}=0.9 \mathrm{~m}$ instead of $L_{c s}=0.5 \mathrm{~m}$. The bearing design yields the same bearing properties as in the reference bridge configuration, since the deck mass is unchanged.

Figure 14 shows the variation with $S_{r}$ of the $D / C$ ratios. The values obtained for this case are very similar to the values obtained for the reference bridge configuration. This is the result of two counteracting effects related to the increase of the bearing eccentricity: an increase of a vertical displacement demand for a given rotation of the pier top, and a decrease of the pier top rotation due to the higher rotational constraint provided by the eccentric bearings for a given value of the translational vertical stiffness.

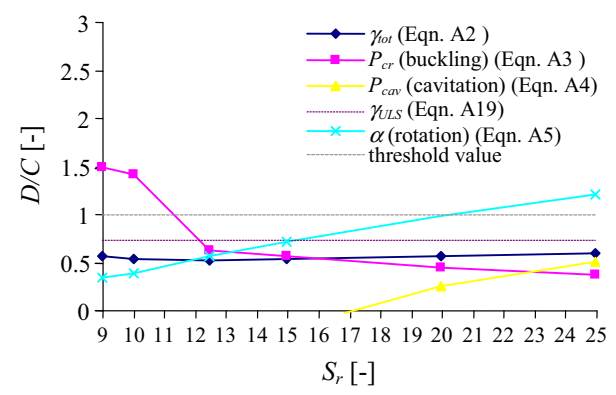

Fig. $14 D / C$ ratios for different limit states versus $S_{r}$ for the case corresponding to an increased bearing eccentricity $e_{b}=1 \mathrm{~m}$ 
For a given value of the shape factor, the values assumed by the moment ratio (denoted by " $e_{b}=1 \mathrm{~m}$ " in Fig. 11) are higher than the corresponding values observed in the reference case, because of the stiffer rotational constraint provided by the eccentric bearings.

\subsection{Influence of the stiffness of the continuity slab}

In order to investigate the influence of the continuity slab, the analyses are carried out again by assuming a zero stiffness value for the element representing it. This is equivalent to assuming that there are expansion joints in place of the continuity slabs between the adjacent deck spans. For this particular case the potential pounding interaction between the adjacent spans is not taken into account, as it was considered that adequate expansion joints prevent the interaction between the spans. The bearing design yields the same bearing properties as in the reference bridge.

Figure 15 a shows the $D / C$ ratios vs. the $S_{r}$. It is seen that there is a high safe factor against cavitation compared to the reference case, corresponding to negative values of the $D / C$ ratio for the cavitation limit state (and thus not reported in the figure) and values of the $D / C$ ratio for the buckling limit state above one only for very low values of $S_{r}$. This behaviour is the consequence of the fact that without the continuity slab there is no rotational restrain at the top of the pier, whose behaviour is similar to that of a cantilever. The plot of the moment ratio (denoted by "no CS" in Fig. 11), which is very small for all the $S_{r}$ values, confirms this observation. It is noteworthy that the moment at the pier top is not equal to zero because of the moments arising due to the rotational stiffness of the bearings and due to the vertical deck motion induced by the pier rotation. This latter contribution is more significant for low $S_{r}$ values because of the higher flexibility in the vertical direction.

Figure 15 b shows the $D / C$ ratios obtained by considering also the vertical component of the seismic excitation. Although this component results in increased values of the axial loads on the bearings, it is still possible to find $S_{r}$ values in the range between 17 and 20 for which all the code safety checks are satisfied.

\subsection{Influence of the deck stiffness}

In order to investigate the influence of the deck flexural stiffness on the bridge response, the analyses were carried out again by assuming a very high stiffness value for the elements representing the deck and the continuity slab. This is only a hypothetical case and may be thought of as representing a continuous multi-span stiff box girder deck supported
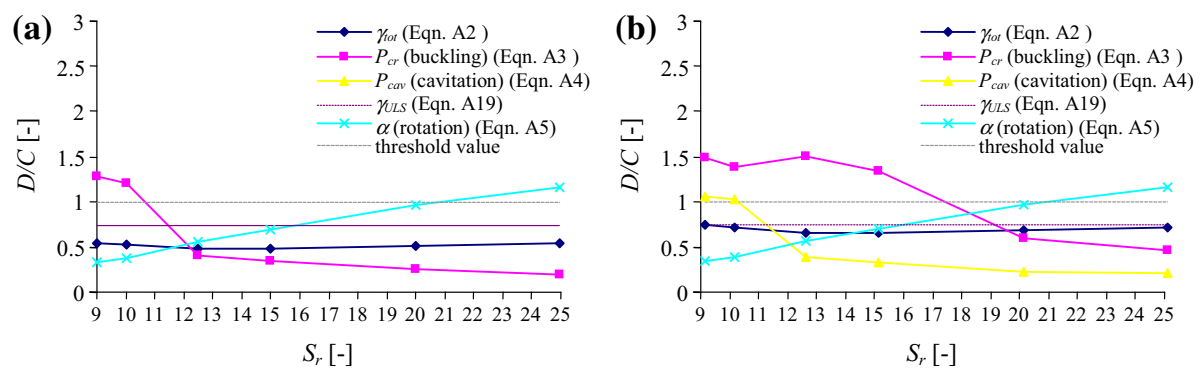

Fig. $15 D / C$ ratios for different limit states versus $S_{r}$ for the case corresponding to a compliant continuity slab: a horizontal component of the seismic input only, b horizontal and vertical component of the seismic input 
on the piers through two lines of bearings. The bearing design yields the same bearing properties as in the reference bridge configuration.

Figure 16 shows the $D / C$ ratios versus the shape factor $S_{r}$. It is seen that the $D / C$ ratio for cavitation exhibits significantly higher values in this case compared to the reference case for values of $S_{r}$ higher than 10 . This trend can be justified by noting that the initial compressive force on the bearings due to vertical loads reduces significantly with respect to the reference case (to about 420 and $440 \mathrm{kN}$ for the bearings at the first and second line), since the very stiff deck transmits higher forces to the abutments than to the piers, which are vertically more flexible. The values assumed by the moment ratio versus the shape factor (denoted by "inf deck" in Fig. 11) are similar to those observed in the reference case.

\subsection{Influence of the pier height}

The height of the piers is assumed to be equal to $H_{p}=20 \mathrm{~m}$, instead of $10 \mathrm{~m}$. The bearing design yields the same bearing properties as in the reference bridge configuration since the pier flexibility is not taken into account during the design process.

The dynamic response of the bridge changes quite significantly due to the increase of the pier flexibility, and, thus it is analysed in detail hereinafter. Figure 17a shows the time history of the pier and deck displacement for record \#1. The value of the pier maximum displacement is significantly higher than the corresponding value observed in the reference case, whereas the deck displacement is not significantly increased. This is the consequence of the higher pier flexibility, which yields also higher values of the pier rotation at its top (Fig. 17b). The mean value of the pier maximum displacement for the various records considered is $0.114 \mathrm{~m}$ (it is $0.031 \mathrm{~m}$ in the reference case), whereas the mean value of the deck displacement is $0.306 \mathrm{~m}$ (it is $0.280 \mathrm{~m}$ for the reference case). Thus, the average horizontal displacement demand of the bearings (respectively 0.226 and $0.223 \mathrm{~m}$ at the two different lines) is reduced in the case of the taller piers with respect to the reference case (respectively 0.258 and $0.261 \mathrm{~m}$ ), as can be seen also in Fig. 18a. At the same time, the higher pier rotation results in higher values of the vertical bearing displacements (Fig. 18a). This yields increased vertical loads induced by the seismic action (Fig. 18b). In fact, by comparing Fig. 18b with Fig. $9 \mathrm{~b}$ it can be observed that both the vertical compressive and tensile displacements exhibit higher values for piers of greater heights. However, for piers of greater heights buckling in compression does not occur due to the lower values of the bearing horizontal displacement, whereas cavitation takes place. In fact, the values of the compressive forces in the bearings of the bridge with tall piers during

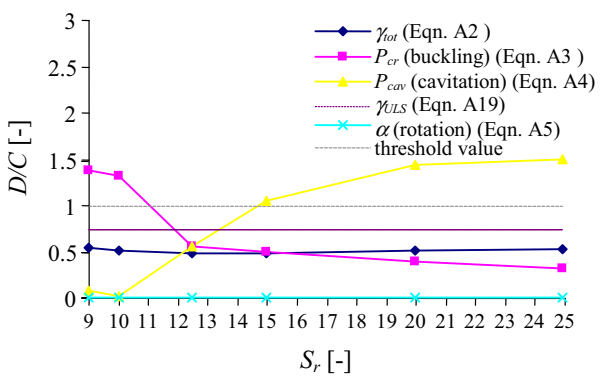

Fig. $16 D / C$ ratios for different limit states versus $S_{r}$ for the case corresponding to stiff deck and continuity slab 
(a)

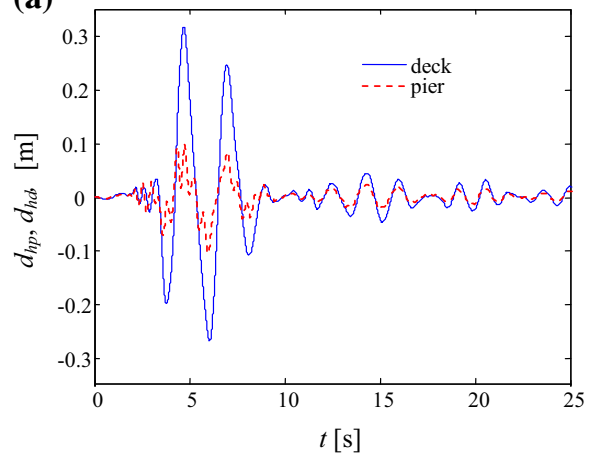

(b)

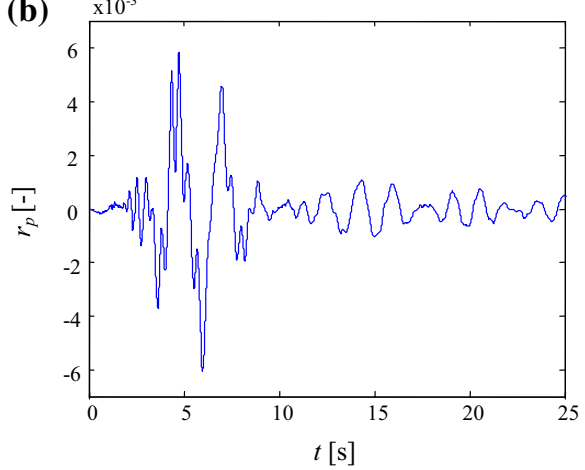

Fig. 17 Time history of a deck and pier top displacement, and of $\mathbf{b}$ pier top rotation
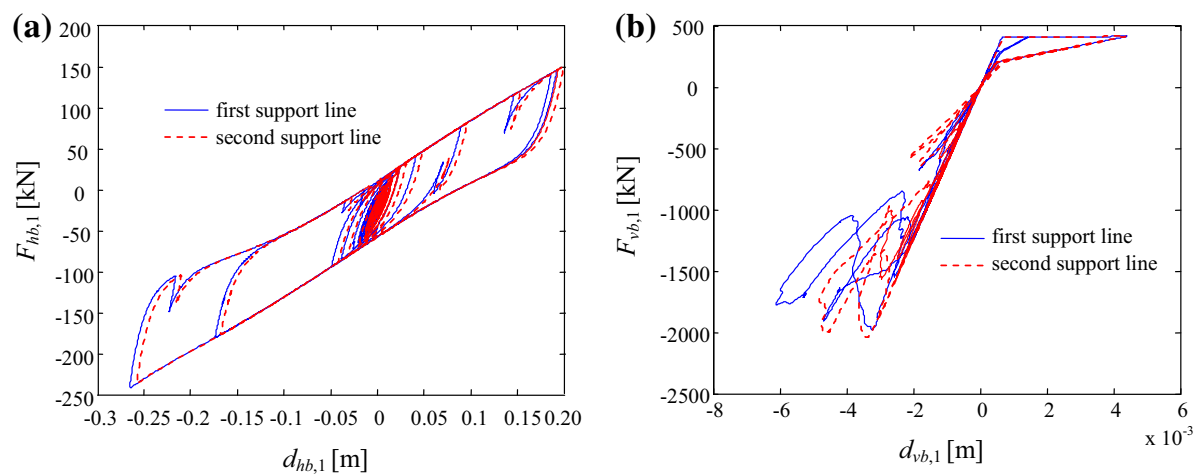

Fig. 18 Hysteretic response of bearings under record \#1 in a shear and $\mathbf{b}$ along the vertical direction under record \#1 for $S_{r}=15$ (model with piers height $H_{p}=20 \mathrm{~m}$, instead of $10 \mathrm{~m}$ ). $\mathrm{d}_{h b, \mathrm{i}}=$ horizontal deflections, $F_{h b, \mathrm{i}}=$ horizontal forces, $\mathrm{d}_{v b, \mathrm{i}}=$ vertical deflections, $F_{v b, \mathrm{i}}=$ vertical forces, $i=1,2$ denote the two bearing lines
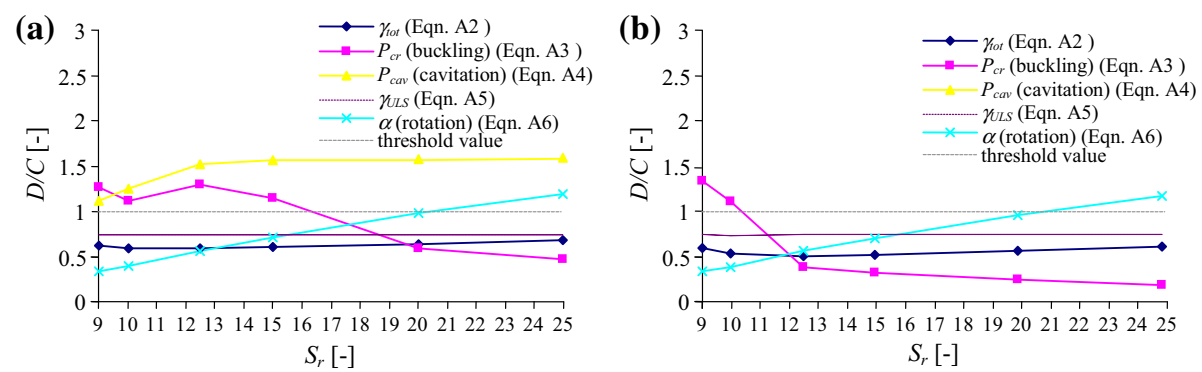

Fig. $19 D / C$ ratios for different limit states versus shape factor $S_{r}$ for the case corresponding to a $H_{p}=20 \mathrm{~m}$, and $\mathbf{b} H_{p}=20 \mathrm{~m}$ and infinitely flexible continuity slab 
the seismic event are always inferior than the critical buckling load, which is equal to $4858.7 \mathrm{KN}$ at zero displacement and reduces to $2757.8 \mathrm{kN}$ at the maximum displacement of $0.265 \mathrm{~m}$.

Figure 19a shows the $D / C$ ratios vs. the shape factor. It is observed that in this case cavitation is in general the most severe limit state, i.e., the $D / C$ ratio for cavitation is always higher than 1 for any $S_{r}$ value. These results suggest that the combination of eccentric isolation bearings and tall piers should be avoided. Alternatively, expansion joints should be used in order to avoid buckling and/or cavitation of the steel-laminated bearings. In fact, by repeating the analyses for a bridge with tall piers and with a continuity slab with zero stiffness it is possible to obtain values of the $D / C$ ratios for the different limit states lower than 1 (Fig. 19b).

By looking at the results plotted in Fig. 11 (denoted by " $H_{p}=20 \mathrm{~m}$ " in Fig. 11) it can be observed that for a given $S_{r}$ value the moment ratio is higher in the case of more flexible piers because of the higher degree of rotational restraint.

\section{Conclusions}

This paper has analysed the potential of occurrence of different limit states in high damping natural rubber (HDNR) bearings employed for isolating multi-span simply-supported isolated bridges. These bridge have the isolators placed eccentrically with respect to the pier axis and this induces significant axial force variation that may lead to the unsatisfactory conditions of cavitation or buckling of the bearings under certain design situations.

In order to shed light on these potential mechanisms and their dependence on the properties of the bearings and of the bridge, a set of bridges representative of design practice has been considered. Finite element models of the bridges have been developed in OpenSees and the behaviour of the isolators has been described through an advanced model, which allows the accurate description of the horizontal and vertical responses as well as their interaction. After investigating in detail the most important characteristics of the seismic response of the reference bridge model, an extensive parametric study has been carried out to identify under which design situations the uplift effect is critical, i.e. for which properties of the superstructure, the substructures, bearings, and pier-to-deck connection (i.e. the eccentricity of the bearings with regards the axis of the pier), the uplift effect is more likely to occur. The performance of the bridge models has been checked against a set of limit states related to the bridge performance and consistent with current codes for earthquake resistance.

Based on the results of the analyses, the following conclusions have been drawn:

1. The vertical response of the bearings is influenced by many factors including the rotation of the pier top and the vertical motion of the deck, which can be significant even if the vertical motion of the seismic input is not considered. Significant coupling is also observed between the horizontal and vertical motion of the bearing, which is accurately described by the bearing model utilised in this paper. SSI effects are also been found to be important for both the horizontal and the vertical response of the isolators, since they influence the deformations of the piers and the bearings.

2. Higher modes to the piers are excited and contribute to the pier top rotation and, thus, influence the vertical deformations of the bearings.

3. The occurrence of different limit states related to the bearing performance is strongly affected by the bearing design, and in particular by the value assumed for the shape factor. In most of the cases buckling of bearings is found to be more critical than 
bearing cavitation, except for the case of piers of great heights and high values of the bearing shape factor.

4. Cavitation can be avoided in most cases by a proper choice of the value of the shape factor during the design stage. The most effective design solution against bearing cavitation and buckling may be the use of a very flexible continuity slab or to avoid it altogether by using expansion joints between adjacent spans. This design solution appears also effective when considering the effects of the vertical component of the seismic action in the analysis, which leads to increased values of the axial force demand in the bearings.

While the authors do not expect the obtained results to be overturned for other types of laminated bearing (such as lead-plug bearings) or bearing models (such as those considering an elasto-plastic response in shear uncoupled from the vertical response), such matters are being addressed in future studies, which will need also to address more deeply the effect of the vertical component of the seismic excitation and the optimal design of the geometrical and mechanical bearing properties.

Acknowledgments Funding for the project Uplift of Elastomeric Bearings in Isolated Bridges, provided by Innovate-UK, is gratefully acknowledged.

Open Access This article is distributed under the terms of the Creative Commons Attribution 4.0 International License (http://creativecommons.org/licenses/by/4.0/), which permits unrestricted use, distribution, and reproduction in any medium, provided you give appropriate credit to the original author(s) and the source, provide a link to the Creative Commons license, and indicate if changes were made.

\section{Appendix: Bearing code requirements}

The requirements of EN15129 (2009) and EN1337-3 (2005) considered in the study are listed hereinafter in the form of synthetic demand/capacity $(D / C)$ ratios that permit to quantify the safety margin with respect to the different limit states. Obviously, $D / C$ values lower or equal to 1 mean that the limit state is not attained, vice versa values higher than 1 denote attainment of the limit state.

In calculating the demand, reference is made to the seismic load combination for EN15129 (2009) and to the ULS combination for EN1337-3 (2005).

\section{EN15129}

- The shear strain $\gamma_{b d, \text { max }}=\frac{d_{b d, \text { max }}}{T_{r}}$ due to the maximum shear displacement $d_{b d \text {,max }}$ calculated as the displacement for the ULS seismic action $d_{E d}$ multiplied by an amplification factor of 1.5 (see EC8-2 2005) should be smaller than 2.5:

$$
(D / C)_{\gamma_{b d, \max }}=\frac{\gamma_{b d, \max }}{2.5} \leq 1
$$

- The maximum total design shear strain $\gamma_{t, d}$ due to the compression load, the shear load, and the rotation should be less than $7 / \gamma_{m}$ :

$$
(D / C)_{\gamma_{t o t}}=\frac{\gamma_{t, d}}{7}=\frac{k_{L}\left(\gamma_{c, E}+\gamma_{q, \max }+\gamma_{\alpha, d}\right)}{7} \leq 1
$$


where:

$-K_{L}=1$;

- $\gamma_{c, E}$ is the design local maximum shear strain due to the compressive strain;

- $\gamma_{q, \max }$ is the design maximum shear strain due to the shear displacement;

- $\gamma_{\alpha, d}$ is the design local maximum shear strain due to rotation. A minimum rotation angle of $0.003 \mathrm{rad}$ shall be assumed for each orthogonal direction in calculating $\varepsilon_{\alpha, d}$.

These strains can be calculated by referring to European Committee for Standardization (ECS) (2009).

- The horizontal deflection capacity (stability) under seismic actions should be checked by checking that $(D / C)_{P c r} \leq 1$, where:

$$
(D / C)_{P c r}= \begin{cases}\frac{\delta}{0.7} & N_{E d} \leq P_{c r} / 4 \\ \frac{N_{E d, \max }}{P_{c r}(1-0.7 \delta)} & P_{c r} / 4 \leq N_{E d} \leq P_{c r} / 2\end{cases}
$$

and where $\delta=\frac{d_{E d}}{a^{\prime}}$ and $a^{\prime}$ is the diameter of the internal reinforcing plates and $P_{c r}$ is the critical buckling load at zero horizontal displacement.

- The value of $N_{E d \text {,min }}$ shall not be a tension force producing a stress greater than $2 G$, where $G$ is the shear modulus measured at $100 \%$ strain:

$$
(D / C)_{P c a v}=\frac{N_{E d, \text { min }}}{2 G A_{r}} \leq 1
$$

where $A_{r}$ is the bearing area.

\section{EN1337-3}

- The maximum value for the shear strains $\gamma_{U L S}$ due to translational movements under the ULS non-seismic load combination should be smaller than 2.5:

$$
(D / C)_{\gamma_{U L S}}=\frac{\gamma_{U L S}}{2.5} \leq 1
$$

In calculating the values of $\gamma_{U L S}$ the effects of temperature, shrinkage and of the breaking forces due to the traffic loads are taken into account.

- For laminated bearings, the rotational limitation shall be satisfied under the ULS nonseismic load combination when:

$$
(D / C)_{\alpha}=\frac{a^{\prime} \cdot \alpha_{d}}{3 \sum v_{z, d}} \leq 1
$$

where

- $\sum v_{z, d}$ is the vertical displacement simultaneous with the rotation $\alpha_{d}$;

$-K_{r, d}=3$ is a rotation factor. 


\section{References}

American Association of State Highway and Transportation Officials (AASHTO) (2014) Guide specifications for seismic isolation design, 4th edn. AASHTO, Washington

Buckle I, Yen W-H, Marsh L, Monzon E (2012) Implications of bridge performance during Great East Japan Earthquake for US seismic design practice. In Proceedings of the international symposium on engineering lessons learned from the 2011 Great East Japan Earthquake, Tokyo, 1-4 Mar 2012, pp 1363-1374

California Department of Transportation (CalTrans) (1999) Bridge memo to designers (20-1)—seismic design methodology. CalTrans, Sacramento

Cardone D, Perrone G (2012) Critical load of slender elastomeric seismic isolators: an experimental perspective. Eng Struct 40:198-204

Cardone D, Dolce M, Palermo G (2009) Direct displacement-based design of seismically isolated bridges. Bull Earthq Eng 7(2):391-410

Cardone D, Palermo G, Dolce M (2010) Direct displacement-based design of buildings with different seismic isolation systems. J Earthq Eng 14(2):163-191

Chen WF, Duan L (eds) (2003) Bridge engineering: seismic design (principles and applications in engineering). CRC Press, Boca Raton

Constantinou MC, Whittaker AS, Kalpakidis Y, Fenz DM, Warn GP (2007) Performance of seismic isolation hardware under service and seismic loading. MCEER-07-0012, Multidisciplinary Center for Earthquake Engineering Research, University at Buffalo, New York

Dezi F, Carbonari S, Leoni G (2013) Lumped parameter model for the time-domain soil-structure interaction analysis of structures on pile foundations. ANIDIS, Padova

Dorfmann A, Burtscher SL (2000) Aspects of cavitation damage in seismic bearings. J Struct Eng 126:573-579

European Committee for Standardization (ECS) (2005a) Structural bearings-Part 3: elastomeric bearings (EN 1337-3). ECS, Brussels

European Committee for Standardization (ECS) (2005b) Eurocode 8: design of structures for earthquake resistance, Part 1: general rules, seismic actions and rules for buildings (EN 1998-1). ECS, Brussels

European Committee for Standardization (ECS) (2005c) Eurocode 8: design of structures for earthquake resistance, Part 2: bridges (EN 1998-2). ECS, Brussels

European Committee for Standardization (ECS) (2009) Anti-seismic devices (EN 15129. ECS, Brussels

Gent AN (1990) Cavitation in rubber: a cautionary tale. Rubber Chem Technol 63:49-53

Gent AN, Lindley PB (1959) Internal rupture of bonded rubber cylinders in tension. Proc R Soc Lond A Math Phys Eng Sci 249(1257):195-205

Grant DN, Fenves GL, Whittaker AS (2004) Bidirectional modelling of high-damping rubber bearings. J Earthq Eng 8:161-185

Iervolino I, Galasso C, Cosenza E (2010) REXEL: computer aided record selection for code-based seismic structural analysis. Bull Earthquake Eng 8(2):339-362

Japan Road Association (JRA) (2002) Chapter 1: seismic design specifications for highway bridges. International Institute of Seismology and Earthquake Engineering, Japan Road Association, Tokyo

Kappos AJ, Saiidi MS, Aydinoglu MN, Isakovic T (2012) Seismic design and assessment of bridges, inelastic methods of analysis and case studies. In: Geotechnical, geological and earthquake engineering. Springer

Katsaras CP, Panagiotakos TB, Kolias B (2009) Effect of torsional stiffness of prestressed concrete box girders and uplift of abutment bearings on seismic performance of bridges. Bull Earthq Eng $7(2): 363-375$

Kelly JM (1997) Earthquake-resistant design with rubber. Springer, London

Koh CG, Kelly JM (1987) Effects of axial load on elastomeric isolation bearings. EERC/UBC 86/12, Earthquake Engineering Research Center, University of California, Berkeley, p 108

Kumar M, Whittaker AS, Constantinou MC (2014) An advanced numerical model of elastomeric seismic isolation bearings. Earthq Eng Struct Dyn 43:1955-1974

Lee GC, Kitane Y, Buckle IG (2001) Literature review of the observed performance of seismically isolated bridges. In: Research progress and accomplishments: multidisciplinary center for earthquake engineering research, pp 51-62

Lesgidis N, Kwon OS, Sextos A (2015) A time-domain seismic SSI analysis method for inelastic bridge structures through the use of a frequency-dependent lumped parameter model. Earthq Eng Struct Dyn 44(13):2137-2156

Makris N, Badoni D, Delis E, Gazetas G (1994) Prediction of observed bridge response with soil-pilestructure interaction. J Struct Eng (ASCE) 120(10):2992-3011 
Manos GC, Mitoulis SA, Sextos A (2012) A knowledge-based software for the design of the seismic isolation system of bridges. Bull Earthq Eng 10(3):1029-1047

McKenna F, Fenves GL, Scott MH (2006) OpenSees: open system for earthquake engineering simulation. Pacific Earthquake Engineering Center, University of California, Berkeley

Mitoulis SA (2014) Uplift of bearings in isolated bridges subjected to longitudinal seismic actions. Struct Infrastr Eng. doi:10.1080/15732479.2014.983527

Muhr AH (2006) Effect of thickness of reinforcing plates on rubber-steel laminated bearings. In: 6th World conference on joints and bearings and seismic systems for concrete structures, Halifax, 17-21 Sept 2006

Muhr AH (2007) Mechanics of Elastomer-Shim laminates. CMC 5(1):11-30

Olmos B, Roesset J (2012) Inertial interaction effects on deck isolated bridges. Bull Earthq Eng 10(3):1009-1028

Pond TJ (1995) Cavitation in bonded natural rubber cylinders repeatedly loaded in tension. J. Nat Rubber Res 10(1):14-25

Tubaldi E, Dall'Asta A (2011) A design method for seismically isolated bridges with abutment restraint. Eng Struct 33(3):786-795

Ucak A, Tsopelas P (2008) Effect of soil-structure interaction on seismic isolated bridges. J Struct Eng 134(7):1154-1164

Warn GP, Whittaker AS, Constantinou MC (2007) Vertical stiffness of elastomeric and lead-rubber seismic isolation bearings. J Struct Eng 133(9):1227-1236

Yang QR, Liu WG, He WF, Feng DM (2010) Tensile stiffness and deformation model of rubber isolators in tension and tension-shear states. J Eng Mech 136:429-437 